Biotechnology

for Biofuels

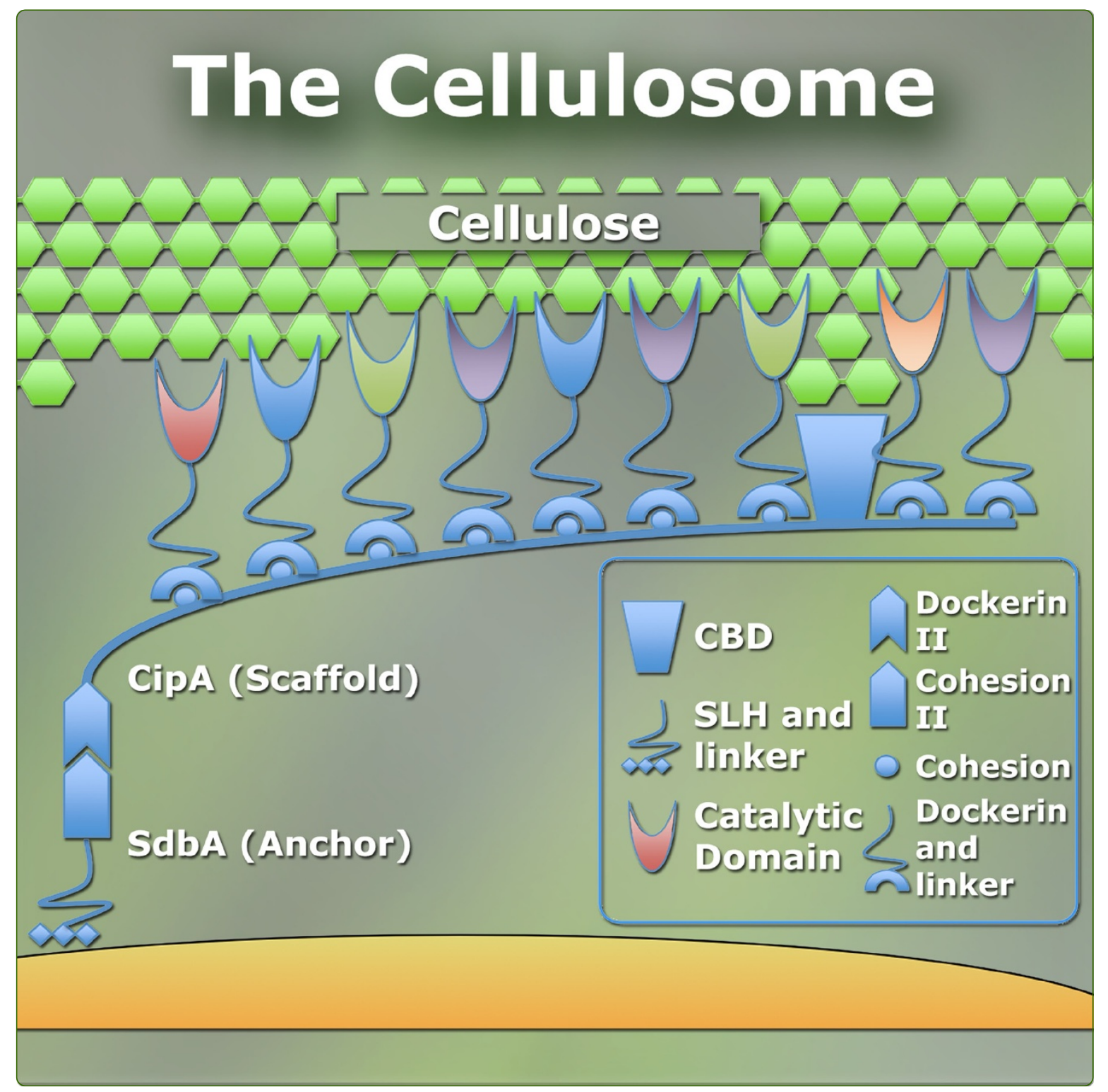

Functional heterologous expression of an engineered full length CipA from Clostridium thermocellum in Thermoanaerobacterium saccharolyticum

Currie et al. 


\title{
Functional heterologous expression of an engineered full length CipA from Clostridium thermocellum in Thermoanaerobacterium saccharolyticum
}

\author{
Devin H Currie ${ }^{1,2}$, Christopher D Herring ${ }^{1}$, Adam M Guss ${ }^{3}$, Daniel G Olson ${ }^{1}$, David A Hogsett ${ }^{2}$ and Lee R Lynd ${ }^{1,2^{*}}$
}

\begin{abstract}
Background: Cellulose is highly recalcitrant and thus requires a specialized suite of enzymes to solubilize it into fermentable sugars. In C. thermocellum, these extracellular enzymes are present as a highly active multi-component system known as the cellulosome. This study explores the expression of a critical $C$. thermocellum cellulosomal component in $T$. saccharolyticum as a step toward creating a thermophilic bacterium capable of consolidated bioprocessing by employing heterologously expressed cellulosomes.

Results: We developed an inducible promoter system based on the native T. saccharolyticum xynA promoter, which was shown to be induced by xylan and xylose. The promoter was used to express the cellulosomal component cip $A^{*}$, an engineered form of the wild-type cipA from C. thermocellum. Expression and localization to the supernatant were both verified for CipA*. When a $\triangle c i p A$ mutant $C$. thermocellum strain was cultured with a CipA*-expressing T. saccharolyticum strain, hydrolysis and fermentation of 10 grams per liter SigmaCell 101, a highly crystalline cellulose, were observed. This trans-species complementation of a cipA deletion demonstrated the ability for CipA* to assemble a functional cellulosome.

Conclusion: This study is the first example of an engineered thermophile heterologously expressing a structural component of a cellulosome. To achieve this goal we developed and tested an inducible promoter for controlled expression in T. saccharolyticum as well as a synthetic cipA. In addition, we demonstrate a high degree of hydrolysis (up to 93\%) on microcrystalline cellulose.
\end{abstract}

Keywords: Thermoanaerobacterium saccharolyticum, Clostridium thermocellum, Cellulosome, Thermophile, Anaerobe, Ethanol, Consolidated bioprocessing

\section{Background}

A long sought goal in the cellulosic ethanol field is onestep solubilization and fermentation without added enzymes $[1,2]$. Such consolidated bioprocessing, or CBP, is considered to be the ultimate low cost approach for cellulose hydrolysis and fermentation [2]. A successful CBP organism must be capable of solubilizing both cellulose and hemicellulose, and also fermenting the resulting sugars to a useful product (e.g., ethanol) at high

\footnotetext{
* Correspondence: Lee.R.Lynd@dartmouth.edu

${ }^{1}$ Thayer School of Engineering, Dartmouth College, Hanover, NH 03755, USA ${ }^{2}$ Mascoma Corporation, Lebanon, NH 03766, USA

Full list of author information is available at the end of the article
}

yield and titer. Unfortunately, no single organism has yet been found or developed that combines these two essential characteristics [3].

Two saccharolytic bacteria of interest for development of CBP-enabling microbes are Clostridium thermocellum and Thermoanaerobacterium saccharolyticum, both Grampositive, thermophilic anaerobes. C. thermocellum exhibits among the highest growth rates on cellulose among described microbes [1], but lacks the ability to ferment hemicellulose. C. thermocellum's ability to solubilize crystalline cellulose, as well as other insoluble components of plant biomass, results from its elaborate, multi-protein cellulase complex or cellulosome [4-7]. T. saccharolyticum

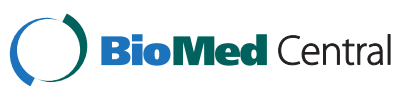


readily solubilizes hemicellulose and ferments all common sugars in biomass, but does not solubilize cellulose. This bacterium is highly amenable to genetic manipulation, indeed exhibiting natural competence, and has been engineered to make ethanol at high yields and titers [8-11].

The component of the $C$. thermocellum cellulosome with the highest molecular weight is the scaffoldin protein, CipA, which has been implicated in mediating the enzymatic synergy seen in the cellulosome $[7,12,13]$. The structure of the $C$. thermocellum CipA includes one cellulose binding domain or CBD, one type II dockerin which is used to associate with cell wall anchoring proteins, and 9 highly conserved type I cohesins interspaced by flexible linker regions [7]. The type 1 cohesin domains bind with high affinity to type 1 dockerin domains present in over 70 catalytically-active enzymes [14].

Previous studies have largely focused on expressing mini cellulosomes, to date with 4 or fewer cohesin regions, or chimeric "designer" cellulosomes in which cohesindockerin pairs from different organisms are used to form complexes with a specified sequence of catalytic proteins [15-31]. Recently a paper reporting in vitro assembly of cellulosomes. To date, there have been no reported attempts to engineer thermophiles to heterologously express a cellulosome, although one attempt has been made to express cellulases [32].

In $C$. thermocellum the presence or absence of CipA has little effect on activity on phosphoric acid swollen cellulose (PASC), carboxymethyl cellulose (CMC), or $\beta$ Glucan, but when absent, results in over an order of magnitude decrease in activity on microcrystalline cellulose $[27,33]$. With this in mind, microcrystalline cellulose was chosen as a test substrate for cellulosome assembly and complementation.

Heterologous expression of a functional cellulosome system in $T$. saccharolyticum is of interest both for fundamentally-oriented studies of microbial cellulose utilization and as a strategy for developing a CBP-enabling microorganism. The logical point of departure for this endeavor is expression of CipA. Here we endeavor to develop an inducible gene expression system in $T$. saccharolyticum, synthesize a gene (cip $\left.A^{*}\right)$ coding for the same amino acid sequence as CipA but with more diversity in the DNA sequences for ease of use, express CipA* in $T$. saccharolyticum, and demonstrate functionality by complementing $\triangle$ cipA mutants of C. thermocellum.

\section{Results}

\section{Construction and testing of xylose/xylan inducible promoter system}

We hypothesized that the promoter and leader sequences of the family 10 endoxylanase $x y n A$ (Tsac_1459) might be useful in expressing and secreting heterologous proteins in T. saccharolyticum. To test this hypothesis, we performed
RT-PCR to determine gene transcription during growth on cellobiose, xylose, and xylan (Figure 1). The results show that $x y n A$ is indeed expressed during growth on xylose or xylan and not glucose. In addition it was also observed to be catabolite repressed when glucose and xylose were both present (data not shown). Next, pMC200, which was designed to remove the $x y n A$ coding region, was transformed into T. saccharolyticum M1442 to confirm that the regions of homology and resistance cassette were sufficient to drive integration and the removal of the $x y n A$ open reading frame. XynA mutants were tested for growth on xylan and xylose with no substantial defect in growth, in agreement with previous results [34].

A second test of the system was performed by replacing $x y n A$ with the His tagged coding region for the secreted $C$. thermocellum family 48 cellulase cel $48 S$ (Clo1313_2747), via pMC212. Expression was confirmed via RT-PCR (Figure 2) and was shown to still be regulated by xylose. Unfortunately, the strain did not produce detectable quantities of Cel48S, and as a result no further work was done with the strain. From these data we concluded the $x y n A$ promoter would function well as an inducible promoter for heterologous gene expression. Furthermore, it allowed cloning of potentially toxic gene products in E. coli. For example, it was found that when $\operatorname{cip} A^{*}$, discussed in detail below, was placed downstream of the native $T$. saccharolyticum ptalack promoter, this resulted in substantial toxic effects to $E$. coli. However, no toxicity issues were seen with the $x y n A$ promoter upstream of $\operatorname{cip} A^{*}$. This indicates that unlike the ptalack promoter the regions of the promoter found on pMC200 were insufficient to drive expression in E. coli in the absence of inducer (xylose).

\section{Design and synthesis of CipA*}

The native $\operatorname{cip} A$ sequence has large repeated regions likely to be problematic for sequencing as well as genetic stability once introduced into $T$. saccharolyticum. To optimize and homogenize cipA for expression and sequencing in $T$. saccharolyticum, we first identified repeated regions,

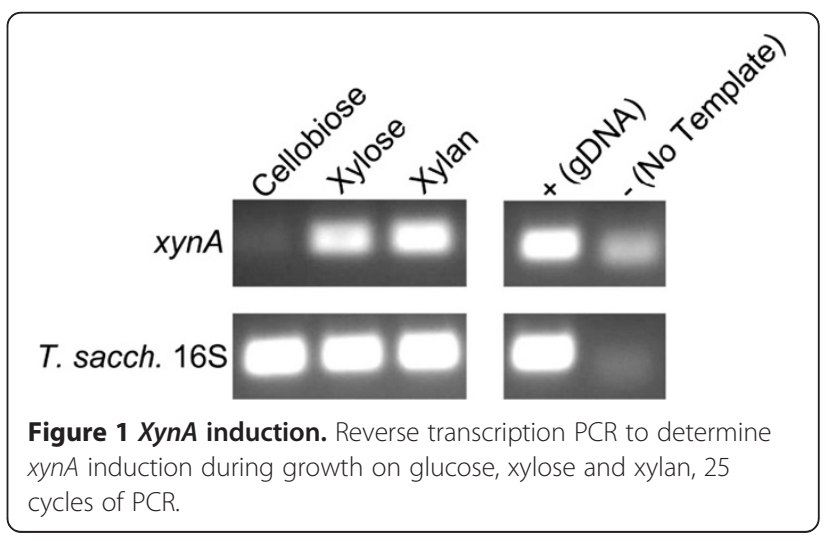




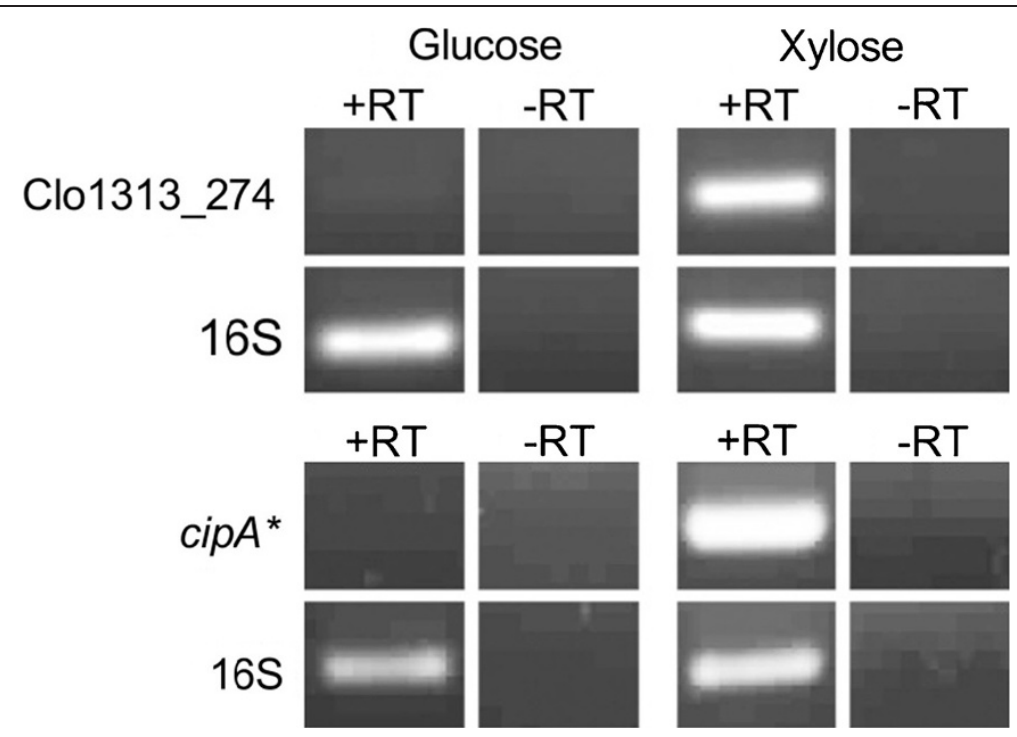

Figure $\mathbf{2} X y n A^{\prime}$ s upstream region as an inducible promoter for use in $\boldsymbol{T}$. saccharolyticum. Reverse Transcriptase PCR analysis of Clo1313_247 and cipA* under the control of the xynA promoter with positive (16S) and negative (no reverse transcriptase added) controls.

the largest 4 of these being identical repeats of almost 500 base pairs (Figure 3). To introduce silent mutations to remove this homology we utilized alternate codons with a minimum usage of $15 \%$ for a given amino acid in predicted T. saccharolyticum open reading frames. By manually and iteratively randomizing which alternate codon was used in a given location we were able to break up the repeated regions without generating extended new homologous sequences. It should also be noted that a standard codon optimization would, rather than rectifying the problem, only serve to enhance the redundancy. The result is $\operatorname{cip} A^{*}$ which has 1325 nucleotide mismatches to the wild type and no unbroken repeats longer than 19 nucleotides while maintaining a wild type amino acid sequence (Figure 3).
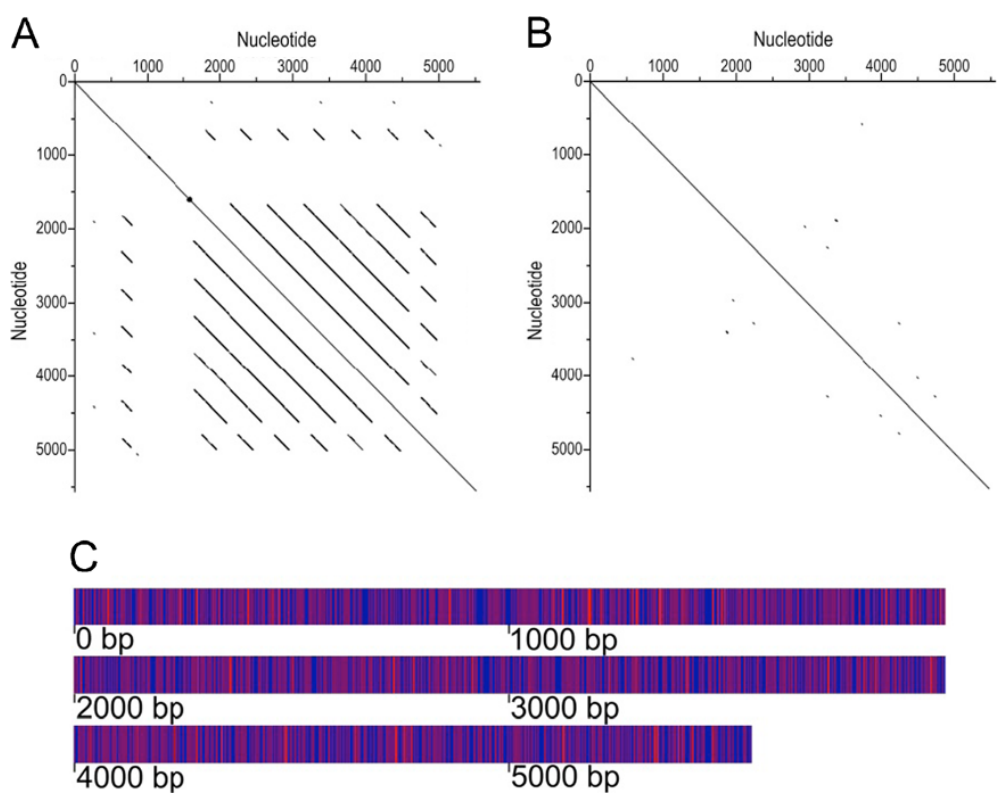

Figure 3 A comparison between the nucleotide sequence of $C$. thermocellum's cipA and the synthetic cipA*. A) A dot matrix analysis of the wild-type cipA with window size of 15 and 0 acceptable mismatches. Positions at which the two sequences are identical at a given position are indicated with a dot. Consecutive identities appear as diagonal lines. B) A dot matrix analysis of the engineered cipA* with window size of 15 and 0 acceptable mismatches. C) Map of single nucleotide polymorphisms between cipA and cipA* with red representing SNPs. 


\section{Expression and localization of CipA*}

CipA, like other cellulosomal components, is secreted via the sec pathway which utilizes an $\mathrm{N}$-terminal signal peptide which is cleaved to liberate the mature protein. In order to assure the His tag's presence in the mature protein, $\operatorname{cip} A^{*}$ was tagged at the $\mathrm{C}$-terminus with a $10 \mathrm{X}$ His tag via a linker (GGGTGHHHHHHHHHH) for detection via western blot.

A number of methods to concentrate $T$. saccharolyticum supernatant were tested including His purification with $\mathrm{Ni}$ beads and FPLC. However, the best results were obtained using molecular weight cut off spin columns. Initial attempts included bacterial or mammalian protease inhibitors, but after it became clear that proteolysis was not an issue, their inclusion was discontinued. Xylose was used as an inducer since it was as effective as xylan (Figure 1) but was more practical to use with spin columns. Unlike in $E$. coli no negative cellular effects were seen as the result of the presence, or induction, of $\operatorname{cip} A^{*}$. The concentrated protein was washed with $20 \mathrm{mM}$ sodium citrate buffer ( $\mathrm{pH}$ 5.7) to remove residual sugars to prevent heavy warping of the protein bands during migration on a SDS-PAGE gel.

Protein isolated from the supernatant and pellet was subject to western blot analysis, probing for the 10X-His tags. CipA* was observed in both the cytoplasm and in the supernatant under inducing conditions (Figure 4) and was absent when grown on glucose (data not shown). To further confirm active secretion and to rule out the possibility of cell lysis as a means of generating CipA* in the supernatant, a second strain was constructed lacking the predicted native sec tag [35] (Additional file 1: Figure S2) and the localization of $\operatorname{cip} A^{*}$ in the two strains was compared. The CipA* derivative lacking a sec tag was only detected in the pellet fraction whereas the CipA* with its sec tag intact was found in both the pellet and the supernatant suggesting lysis was not responsible for presence of

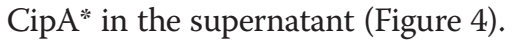

Our initial attempts using the standard $100^{\circ} \mathrm{C}$ denaturation in preparation for running an SDS-PAGE resulted

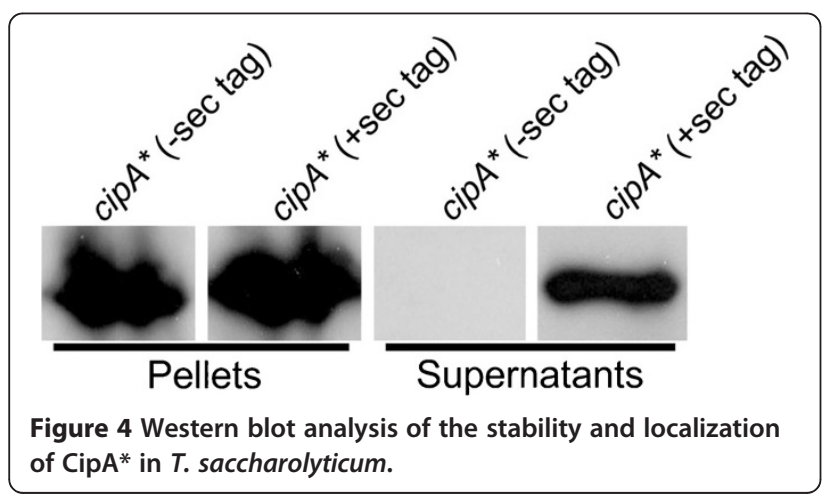

in protein cleavage as others have also observed for $\operatorname{cip} A$ $[36,37]$. However, when the denaturation temperature was dropped, or time was decreased, we obtained a single intact band.

\section{Interspecies complementation}

Co-cultures of C. thermocellum and T. saccharolyticum were used to test the functionality of heterologously expressed CipA*. We utilized a cipA deletion strain of C. thermocellum that shows markedly impaired growth on microcrystalline cellulose but still produces cellulosomal components other than CipA when cultivated on cellobiose. By co-culturing $C$. thermocellum $\triangle$ cipA with the strain of T. saccharolyticum that expresses CipA*, we hypothesized that $\mathrm{CipA}^{*}$, if functional, would complement the deletion in C. thermocellum and act as a scaffold thus restoring the ability to hydrolyze cellulose. To evaluate the co-culture's ability to hydrolyze cellulose we determined residual cellulose/dry weight and product formation (Figure 5).

The wild type C. thermocellum performed well with respect to cellulose hydrolysis as measured by dry weight. The observed low product formation and unfermented sugars seen with wild type $C$. thermocellum are most likely the result of the low starting $\mathrm{pH}$ and the lack of $\mathrm{pH}$ control resulting in a discontinuation of metabolic, but not enzymatic hydrolysis activity later in growth. No strain of T. saccharolyticum alone appeared to have any effect on cellulose, but grew entirely on the supplied xylose, nor did the wild type strain of $T$. saccharolyticum rescue the cellulose hydrolysis defect in C. thermocellum strain DS11. Only T. saccharolyticum expressing cipA* (strain DHC15) was able to restore cellulose hydrolysis functionality to the C. thermocellum $\triangle$ cipA (strain DS11).

Finally, we wished to confirm that populated cellulosomes were being formed. Cellulosomes were purified via affinity digestion from co-cultures between DHC15 and DS11 and compared via native PAGE to those from wild type $C$. thermocellum and concentrated supernatants from DHC15 and DS11 grown indivigually (Additional file 2: Figure S3). As expected neither DHC15 nor DS11 were able to form cellulosomes when grown independently. When DHC15 and DS11 were grown together cellulosomes were produced with an identical native PAGE migration as those from wild type $C$. thermocellum.

These data demonstrate that the $T$. saccharolyticumproduced CipA* is capable of gathering and displaying functional cellulosomal enzymes. In addition, the appearance of the pellet further supported the removal of cellulose from the wild type $C$. thermocellum and the co-cultures of $\operatorname{cip}^{*}$ and $\triangle \operatorname{cip} A$ as these dry pellets were nearly translucent, suggesting only cell debris, rather than the white cellulose observed in the other samples. 


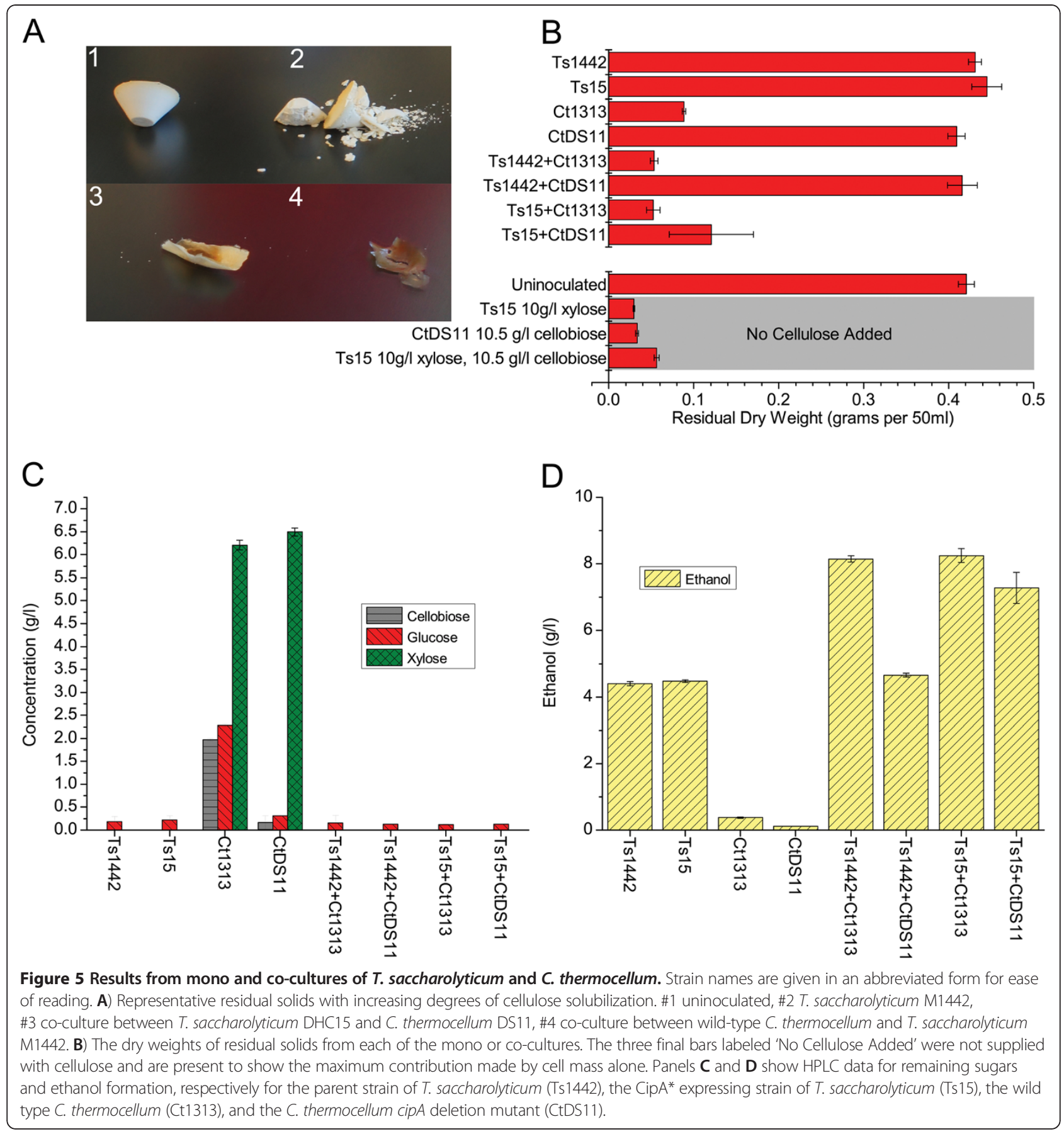

\section{Discussion}

Here we report the expression of an engineered CipA* under the control of a novel inducible promoter in $T$. saccharolyticum which allowed for the assembly of active cellulosomes when co-cultured with a $\operatorname{cipA}$ deletion strain of C. thermocellum.

The wild-type cipA gene has multiple sections with essentially identical DNA sequences, corresponding to the 9 type-I dockerin regions [7]. These repeated sequences can be problematic by complicating sequence verification via routine sequencing technology and could also lead to unwanted partial gene deletion via homologous recombination. Many strains of $E$. coli used to heterologously express cellulosomal proteins for biochemical studies are recA- $[24,27,38]$. However, studies such as this one which seek to integrate cellulase genes into the chromosome via native host machinery must use $r e c A+$ strains thereby exacerbating the challenge of homologous recombination. 
By using $\operatorname{cip} A^{*}$, designed to avoid repeated sequences, routine sequencing proceeded without difficulty and homologous recombination was not observed.

Toxicity has been observed by other groups working with heterologous expression of $\operatorname{cip} A$, and were solved, at least in part, by using inducible promoters in $E$. coli and Lactococcus lactis [23,27]. For this and other reasons we wished to express $\operatorname{cip} A^{*}$ under the control of an inducible promoter. As there have been no inducible promoter systems described for $T$. saccharolyticum we designed and tested one based on $x y n A$ 's promoter. We chose this promoter due to the fact that XynA has been shown to be non-essential [34] and thus could be replaced with a gene of interest. We found that the $x y n A$ promoter avoided toxicity effects in both E. coli and $T$. saccharolyticum, although apparent toxicity was encountered using the pta/ack promoter.

In past in vitro heterologous cellulosome expression reports significant hydrolysis of microcrystalline cellulose was either not achieved or not tested, with one exception reaching $45 \%$ hydrolysis [15,17,18,23,25,28-31]. In the data reported here if we remove the contribution of cell mass to the dry weights and compare that to the uninoculated bottles we see that total cellulose solubilization is between 98 and 100 percent for the co-culture of the CipA* expressing T. saccharolyiticum and the wild-type $C$. thermocellum, and between 71 and 93 percent for the CipA* expressing T. saccharolyiticum and $C$. thermocellum $\triangle$ cipA. While the trans-complementation co-culture can achieve close to wild type co-culture solubilization in some cases, it is rather variable. The lower hydrolysis from the CipA* expressing T. saccharolyticum and $C$. thermocellum $\triangle$ cipA co-culture, as compared to that of wild-type C. thermocellum, may be the result of one or more effects. First, while the cohesin dockerin interaction is quite robust, it is possible that when produced by two different strains the assembly of mature cellulosomes occurs less efficiently than if the components are being secreted simultaneously from the same cell $[39,40]$. Second, the assembled cellulosomes are incapable of adhering to the surface of the more metabolically active $T$. saccharolyticum, and thus are either present free in the media or bound to the surface of $C$. thermocellum's via the native anchor proteins [41-43]. This could result in local product inhibition, and may contribute to the lower than expected hydrolysis [3,44-46].

Krauss et al. found that CipA purified from E. coli was populated with cellulosomal enzymes present in $C$. thermocellum supernatants and had near wild-type activity on microcrystalline cellulose [27]. These results led the authors to conclude that the cohesin dockerin interactions are the primary means of cellulosome assembly, an interpretation which our work also supports. Whereas Krauss et al. reported cellulosome assembly in vitro, we demonstrate here assembly from components produced by growing cultures with heterologous production using a host that has a temperature optimum compatible with that of the C. thermocellum cellulosome.

In both Krauss et al. and this study, cellulosomes derived from components produced in separate organisms but otherwise unmodified are found to exhibit similar, although somewhat lower, activity on crystalline cellulose as compared to controls with components produced by a single organism. By contrast, studies involving "designer cellulosomes", in which specific catalytic components bind in a specific order to chimeric scaffoldins, either report several-fold lower activity on crystalline cellulose compared to controls or do not report activity on crystalline cellulose at all. This difference could be because of the importance of a diverse population of cellulosomes with randomly-combined catalytic components, the smaller size of chimeric scaffoldins used in designer cellulosome work, or a combination. The model system reported here, featuring full-sized engineered scaffoldins, is a promising platform for understanding these effects.

An unexpected result of the expression and purification of CipA* in T. saccharolyticum was the observed instability upon high temperature treatment with SDSPAGE loading buffer present. While a similar effect has been reported by Morag and Lamed in C. thermocellum, the conditions used to achieve this result are markedly different $[36,37]$. In the previous reports, purified protein was subjected to low $\mathrm{pH}$ (3.5) or low ionic strength (dialyzed against double distilled water overnight) which resulted in the cleavage of an Asp-Pro peptide bond present in the cohesin domain of CipA. In contrast, no harsh conditions were applied to CipA* from $T$. saccharolyticum with supernatant $\mathrm{pHs}$ staying above 5.8 and with no dialysis treatment applied. This may indicate a considerable difference between the extracellular environment developed by cultures of $C$. thermocellum compared to that of $T$. saccharolyticum, and could be important in future attempts at heterologous cellulosome expression.

\section{Conclusion}

Combined with the native ability of T. saccharolyticum to utilize hemicellulose and the availability of engineered strains that produce ethanol at high yield and titer $[8,11]$, a strain of $T$. saccharolyticum with the ability to solubilize cellulose would be a strong candidate organism for CBP. Our results, including expression and secretion of a functional, engineered, full-length CipA, represent a step toward developing such an organism. In addition, we demonstrate a model system in which understanding cellulolytic organisms and their enzyme systems can be tested by systematically reconstructing them. 


\section{Methods}

\section{Microorganisms and growth media}

The parent strain for all $T$. saccharolyticum strains is M1442 [47], engineered with deletions of the genes for phosphotransacetylase, acetate kinase, and lactate dehydrogenase and expressing genes for urea utilization from C. thermocellum which serve to buffer acid production [11]. C. thermocellum DSM1313 was obtained from DSMZ (Deutsche Sammlung von Mikroorganismen und Zellkulturen $\mathrm{GmbH}$, Germany). C. thermocellum strain DS11, a cipA deletion mutant, was generated in our laboratory and is derived from C. thermocellum DSM1313 $\Delta h p t$ and was supplied by D. G. Olson [48]. All T. saccharolyticum strains were grown in modified DSMZ M122 medium [9] with $10 \mathrm{~g} / \mathrm{l}$ xylose or xylan where noted, $0.5 \mathrm{~g} / \mathrm{l}$ urea at $\mathrm{pH} 6.3$ and $55^{\circ} \mathrm{C}$ unless otherwise stated. C. thermocellum strains were grown in M122 with $10 \mathrm{~g} / \mathrm{l}$ cellobiose, $\mathrm{pH} 7.0$ at $55^{\circ} \mathrm{C}$. All cultures were grown in a Coy anaerobic chamber under a nitrogen, carbon dioxide, and hydrogen gas mix unless otherwise noted.

\section{Plasmid and strain construction}

All plasmids were constructed in Saccharomyces cerevisiae FY2 [49] via yeast mediated homologous recombination [50], isolated from yeast with a Zymoprep Yeast Plasmid Miniprep II (Zymo Research, Irvine, CA) and transformed into chemically competent Invitrogen $E$. coli TOP10 (Invitrogen Corp, Carlsbad, CA) to generate sufficient quantities of plasmid for transformation into $T$. saccharolyticum. Plasmids were then isolated from E. coli with the QIAGEN Plasmid Mini kit (QIAGEN Inc, Hilden, Germany). T. saccharolyticum was transformed with plasmid DNA as previously described in a Coy anaerobic chamber [9]. Plasmids and strains are listed in Table 1. Genotypic confirmation for modified strains was obtained via PCR and sequencing. CipA* was synthesized by GeneArt (Additional file 3: Figure S1) [51].

\section{Reverse transcription PCR}

RNA was isolated from cultures of $T$. saccharolyticum incubated overnight at $55^{\circ} \mathrm{C}$ in modified M122 [9] with

Table 1 Strains, plasmids, and primers used in this study

\begin{tabular}{|c|c|c|}
\hline Strain & Description and characteristics & Reference \\
\hline T. sacch. M1442 & High titer ethanol producing strain & Lee et al., 2011 [47] \\
\hline T. sacch. DHC6 & T. sacch $\Delta x y n A:: C l o 1313 \_2747$ & This study \\
\hline T. sacch. DHC15 & T. sacch $\Delta x y n A::$ cipA* (wild type sec tag) & This study \\
\hline T. sacch. DHC16 & T. sacch $\Delta x y n A: . c i p A^{*}$ (with a deletion in the sec tag) & This study \\
\hline C. therm. DSM 1313 & C. therm wild type obtained from DSMZ culture collection & DSMZ \\
\hline C. therm. DS11 & C. therm $1313 \Delta$ cipA & Olson et al. 2013 [48] \\
\hline E. coli TOP 10 & Chemically competent & Invitrogen \\
\hline S. cerevisiae FY2 & Uracil Auxotroph used for homologous recombination & Winston et. al, 1995 [49] \\
\hline Plasmid & Description and characteristics & Reference \\
\hline pMC200 & Deletes $x y n A$ and replaces it with a kanamycin resistance gene and a removable marker & This study \\
\hline pMC212 & Replaces xynA with Clo1313_2747, a kanamycin resistance gene, and a removable marker & This study \\
\hline pMC213 & Replaces xynA with cipA*, a kanamycin resistance gene, and a removable marker & This study \\
\hline pMC223 & Replaces xynA with $\Delta$ sec tag $c i p A^{*}$, a kanamycin resistance gene, and a removable marker & This study \\
\hline Primer & Sequence & Reference \\
\hline xynA_RT_F & TACTTCAGGATGGGTTGGAACAGG & This study \\
\hline xynA_RT_R & TCCAATTAGCTGTTCTCCCTGTCG & This study \\
\hline gamA_RT_F & ATATTCACCAGCAACGCTGGCTTC & This study \\
\hline gamA_RT_R & AATAAGCCTITGCCAGTTGTCCGC & This study \\
\hline Clo1313_2747_RT_F & AGTGGCGTTATACAAACGCTCCTG & This study \\
\hline Clo1313_2747_RT_R & ATACAACGGAAGCAACGGCAGAAC & This study \\
\hline cipA*_RT_F & ACGACTATCTITGCCGCTATGATCCC & This study \\
\hline cipA*_RT_R & ACTTAGATCCTACGGCAGCAGTGAC & This study \\
\hline pMC200_up_F & gtctttcgactgagcctttcgttttatttgatgcctggatcttttctggectttaatggcg & This study \\
\hline pMC200_up_R & cagctgaagcttcccggggatcctctagagaattcgagctctcttacttcctccctcagtaaatttaatttattg & This study \\
\hline pMC200_down_F & ctagataggggtcccgagcgcctacgaggaatttgtatcgaaaaaacaaataatctttaagtaaaaaggcagagagg & This study \\
\hline pMC200_down_R & ccgtcagtagctgaacaggagggacagctgatagaagtcaaatgcgacaaaaaaacgcc & This study \\
\hline
\end{tabular}


$10 \mathrm{~g} / \mathrm{l}$ glucose, xylose, or xylan. RNA was purified with the QIAGEN RNeasy Mini Kit and stored at $-80^{\circ} \mathrm{C}$. cDNA was generated with the QIAGEN QuantiTect Reverse Transcription Kit. The resulting cDNA was examined for the presence of the transcripts of interest using the primers listed in Table 1.

\section{Insertion of CipA* into the chromosome}

Insertion of cipA* into the chromosome under the control of the xynA promoter was achieved via double homologous recombination, selected for by the presence of a kanamycin resistance marker on a nonreplicative plasmid $\mathrm{pMC} 213$. The sites of recombination were directly upstream of the start codon and downstream of the stop codon in the xynA open reading frame. The size of these regions of homology was 1000 base pairs each, and left the ribosome binding site from $x y n A$ intact.

\section{Western blot analysis of his-tagged proteins}

T. saccharolyticum strains were grown to $2 / 3$ maximum OD600. Cells were pelleted, supernatants were filter sterilized and concentrated with Vivaspin 20, PES 10,000 molecular weight cut off centrifugal concentrators (Sartorius Stedim Biotech) as per the manufacturer's instructions. Samples were washed with two volumes of sodium citrate buffer $(20 \mathrm{mM}, \mathrm{pH} 5.7)$ at $15^{\circ} \mathrm{C}$. Pellets were treated with $20 \mathrm{mg} / \mathrm{ml} \mathrm{lysozyme} \mathrm{in} \mathrm{SET} \mathrm{buffer} \mathrm{(40} \mathrm{mM} \mathrm{EDTA,} 50 \mathrm{mM}$ Tris- $\mathrm{HCl}, \mathrm{pH} 8.0,0.75 \mathrm{M}$ sucrose) for 10 minutes to remove the cell wall, pelleted and resuspended in lysis buffer (10 mM Tris pH 7, 0.2\% SDS, $1 \mathrm{mM} \mathrm{DTT)} \mathrm{and} \mathrm{incubated}$ at $55^{\circ} \mathrm{C}$ for 15 minutes. Proteins were denatured at $55^{\circ} \mathrm{C}$ in loading buffer (5X loading buffer: $6.25 \mathrm{ml} 1 \mathrm{M}$ Tris $\mathrm{pH}$ 6.8, $2 \mathrm{ml}$ glycerol, $7.3 \mathrm{~g}$ SDS, bromophenol blue $0.1 \%$, final $\mathrm{pH}$ 6.8). Total protein from either supernatants or lysed cell pellets were analyzed via Western blot with mouse Penta-His (Cat. No. 34660, QIAGEN Inc.) primary, and goat anti-mouse peroxidase conjugate (Cat. No. 31439, Thermo Sci.) secondary antibody. Detection was performed with Western Lightning ECL substrate (PerkinElmer, Waltham, MA) and detected on Kodak X-ray film.

\section{Co-cultures}

$50 \mathrm{ml}$ co-cultures were grown in $115 \mathrm{ml}$ nitrogen flushed anaerobic serum bottles agitated in an incubator at $55^{\circ} \mathrm{C}$. The medium for the co-cultures was modified DSMZ M122 [9] with $10 \mathrm{~g} / \mathrm{l}$ xylose and $10 \mathrm{~g} / \mathrm{l}$ Sigmacell 101 (a microcrystalline cellulose similar to avicel) and $0.5 \mathrm{~g} / \mathrm{l}$ cellobiose to assist in the initial growth of $C$. thermocellum. The initial $\mathrm{pH}$ was $\mathrm{pH} 6.3$, previously demonstrated to be suitable for co-cultures between these two organisms [52]. Co-cultures were allowed to grow for 5 days. Cellulosomes were purified via affinity digestion of PASC [27].

\section{Product formation and dry weight}

Dry weight was determined by pelleting the remaining cellulose via centrifugation for 10 minutes at $8000 \mathrm{~g}$, washing twice with deionized water, and drying at $45^{\circ} \mathrm{C}$ under vacuum for 2 days. Dried pellets were then weighed to determine residual solids. The contribution of cell mass was taken into account with controls containing $10 \mathrm{~g} / \mathrm{l}$ cellobiose in place of Sigmacell. Residual sugars and ethanol in the supernatants were quantified by HPLC using an Aminex HPX-87H column (Bio-Rad Laboratories, Hercules, CA). Nucleotide sequence accession number.The sequences reported in this paper have been deposited in the GenBank database (accession no. KC675188 [pMC200], KC675189 [pMC212], KC675190 [pMC213], and KC675191 [pMC223]).

\section{Additional files}

Additional file 1: Sequence of $\operatorname{cip} A^{*}$ minus the predicted signal peptide with a C-terminal 10X his tag and linker region.

Additional file 2: Coomassie stained native PAGE of trans-species formed cellulosomes.

Additional file 3: Sequence of cipA* with a C-terminal $10 \mathrm{X}$ his tag and linker region.

\section{Abbreviations}

CBP: Consolidated bioprocessing; CBD: Cellulose binding domain; PASC: Phosphoric acid swollen cellulose; CMC: Carboxymethyl cellulose.

\section{Competing interests}

This research was supported in part by Mascoma Corporation, Lebanon $\mathrm{NH}$ with which authors DHC, CDH, DAH and LRL are affiliated. Mascoma Corporation has a commercial interest in the organisms used in this study. The authors DHC and AMG are listed on the international and national pending patents for the sequence of cipA* [52]

\section{Authors' contributions}

DHC performed the work presented herein and drafted the manuscript. DGO assisted in drafting the manuscript. $C D H, A M G, D A H$ and LRL supervised the work and assisted in drafting the manuscript. All authors read and approved the final manuscript.

\section{Acknowledgments}

We would like to thank Dr. Joe Shaw and Dr. Erin Wiswall of Mascoma Corporation for providing strains, plasmids, methodological training, and advice. We would like to thank Alicia Eve Ballok for critical reading of the manuscript.

This research was supported by Mascoma Corporation, Lebanon $\mathrm{NH}$, the Department of Energy under Award Number DE-FC36-07G017057, and by the BioEnergy Science Center (BESC), Oak Ridge National Laboratory. The BioEnergy Science Center is a U.S. Department of Energy Bioenergy Research Center supported by the Office of Biological and Environmental Research in the DOE Office of Science.

\section{Disclaimer}

"This report was prepared as an account of work sponsored by an agency of the United States Government. Neither the United States Government nor any agency thereof, nor any of their employees, makes any warranty, express or implied, or assumes any legal liability or responsibility for the accuracy, completeness, or usefulness of any information, apparatus, product, or process disclosed, or represents that its use would not infringe privately owned rights. Reference herein to any specific commercial product, process, or service by trade name, trademark, manufacturer, or otherwise does not necessarily constitute or imply its endorsement, recommendation, or 
favoring by the United States Government or any agency thereof. The views and opinions of authors expressed herein do not necessarily state or reflect those of the United States Government or any agency thereof."

\section{Author details}

'Thayer School of Engineering, Dartmouth College, Hanover, NH 03755, USA. ${ }^{2}$ Mascoma Corporation, Lebanon, NH 03766, USA. ${ }^{3}$ Oak Ridge National Laboratory, Oak Ridge, TN 37831, USA.

\section{Received: 6 November 2012 Accepted: 8 February 2013}

Published: 1 March 2013

\section{References}

1. Lynd LR, Weimer PJ, van Zyl WH, Pretorius IS: Microbial cellulose utilization: fundamentals and biotechnology. Microbiol Mol Biol Rev 2002, 66:506-577. table of contents.

2. Lynd LR, van Zyl WH, McBride JE, Laser M: Consolidated bioprocessing of cellulosic biomass: an update. Curr Opin Biotechnol 2005, 16:577-583.

3. Olson DG, McBride JE, Joe Shaw A, Lynd LR: Recent progress in consolidated bioprocessing. Curr Opin Biotechnol 2012, 23:396-405.

4. Lamed R, Setter E, Bayer EA: Characterization of a cellulose-binding, cellulase-containing complex in Clostridium thermocellum. J Bacteriol 1983, 156:828-836.

5. Bayer EA, Setter E, Lamed R: Organization and distribution of the cellulosome in Clostridium thermocellum. J Bacteriol 1985, 163:552-559.

6. Beguin P, Lemaire M: The cellulosome: an exocellular, multiprotein complex specialized in cellulose degradation. Crit Rev Biochem Mol Biol 1996, 31:201-236.

7. Bayer EA, Belaich JP, Shoham Y, Lamed R: The cellulosomes: multienzyme machines for degradation of plant cell wall polysaccharides. Annu Rev Microbiol 2004, 58:521-554.

8. Shaw AJ, Podkaminer KK, Desai SG, Bardsley JS, Rogers SR, Thorne PG, Hogsett DA, Lynd LR: Metabolic engineering of a thermophilic bacterium to produce ethanol at high yield. Proc Natl Acad Sci U S A 2008, 105:13769-13774

9. Shaw AJ, Hogsett DA, Lynd LR: Natural competence in Thermoanaerobacter and Thermoanaerobacterium species. Appl Environ Microbiol 2010, 76:4713-4719.

10. Shaw AJ, Covalla SF, Hogsett DA, Herring CD: Marker removal system for Thermoanaerobacterium saccharolyticum and development of a markerless ethanologen. Appl Environ Microbiol 2011, 77:2534-2536.

11. Shaw JA, Covalla SF, Miller BB, Firliet BT, Hogsett DA, Herring CD: Urease expression in a Thermoanaerobacterium saccharolyticum ethanologen allows high titer ethanol production. Metab Eng 2012, 14:528-532.

12. Bayer EA, Shimon LJ, Shoham Y, Lamed R: Cellulosomes-structure and ultrastructure. J Struct Biol 1998, 124:221-234.

13. Gilbert HJ: Cellulosomes: microbial nanomachines that display plasticity in quaternary structure. Mol Microbio/ 2007, 63:1568-1576.

14. Zverlov W, Kellermann J, Schwarz WH: Functional subgenomics of Clostridium thermocellum cellulosomal genes: identification of the major catalytic components in the extracellular complex and detection of three new enzymes. Proteomics 2005, 5:3646-3653.

15. Hyeon JE, Yu KO, Suh DJ, Suh YW, Lee SE, Lee J, Han SO: Production of minicellulosomes from Clostridium cellulovorans for the fermentation of cellulosic ethanol using engineered recombinant Saccharomyces cerevisiae. FEMS Microbiol Lett 2010, 310:39-47.

16. Tsai SL, Goyal G, Chen W: Surface display of a functional minicellulosome by intracellular complementation using a synthetic yeast consortium and its application to cellulose hydrolysis and ethanol production. Appl Environ Microbiol 2010, 76:7514-7520.

17. Hyeon JE, Jeon WJ, Whang SY, Han SO: Production of minicellulosomes for the enhanced hydrolysis of cellulosic substrates by recombinant Corynebacterium glutamicum. Enzyme Microb Technol 2011, 48:371-377.

18. Goyal G, Tsai SL, Madan B, DaSilva NA, Chen W: Simultaneous cell growth and ethanol production from cellulose by an engineered yeast consortium displaying a functional mini-cellulosome. Microb Cell Fact 2011, 10:89.

19. Anderson TD, Robson SA, Jiang XW, Malmirchegini GR, Fierobe HP, Lazazzera BA, Clubb RT: Assembly of minicellulosomes on the surface of Bacillus subtilis. Appl Environ Microbiol 2011, 77:4849-4858.
20. Sun J, Wen F, Si T, Xu JH, Zhao H: Direct conversion of xylan to ethanol by recombinant Saccharomyces cerevisiae strains displaying an engineered minihemicellulosome. Appl Environ Microbiol 2012, 78:3837-3845.

21. Caspi J, Irwin D, Lamed R, Li Y, Fierobe HP, Wilson DB, Bayer EA: Conversion of Thermobifida fusca free exoglucanases into cellulosomal components: comparative impact on cellulose-degrading activity. J Biotechno/ 2008, 135:351-357.

22. Caspi J, Barak Y, Haimovitz R, Irwin D, Lamed R, Wilson DB, Bayer EA: Effect of linker length and dockerin position on conversion of a Thermobifida fusca endoglucanase to the cellulosomal mode. Appl Environ Microbiol 2009, 75:7335-7342.

23. Wieczorek AS, Martin VJ: Engineering the cell surface display of cohesins for assembly of cellulosome-inspired enzyme complexes on Lactococcus lactis. Microb Cell Fact 2010, 9:69.

24. Fierobe HP, Bayer EA, Tardif C, Czjzek M, Mechaly A, Belaich A, Lamed R, Shoham Y, Belaich JP: Degradation of cellulose substrates by cellulosome chimeras. Substrate targeting versus proximity of enzyme components. J Biol Chem 2002, 277:49621-49630.

25. Mingardon F, Perret S, Belaich A, Tardif C, Belaich JP, Fierobe HP: Heterologous production, assembly, and secretion of a minicellulosome by Clostridium acetobutylicum ATCC 824. Appl Environ Microbiol 2005, 71:1215-1222.

26. Morais S, Barak Y, Caspi J, Hadar Y, Lamed R, Shoham Y, Wilson DB, Baye EA: Cellulase-xylanase synergy in designer cellulosomes for enhanced degradation of a complex cellulosic substrate. MBio 2010, 1:e00285-00210.

27. Krauss J, Zverlov W, Schwarz WH: In vitro reconstitution of the complete Clostridium thermocellum cellulosome and synergistic activity on crystalline cellulose. App/ Environ Microbiol 2012, 78:4301-4307.

28. Wen F, Sun J, Zhao H: Yeast surface display of trifunctional minicellulosomes for simultaneous saccharification and fermentation of cellulose to ethanol. Appl Environ Microbiol 2010, 76:1251-1260.

29. Cho HY, Yukawa H, Inui M, Doi RH, Wong SL: Production of minicellulosomes from Clostridium cellulovorans in Bacillus subtilis WB800. Appl Environ Microbiol 2004, 70:5704-5707.

30. Lilly M, Fierobe HP, van Zyl WH, Volschenk H: Heterologous expression of a Clostridium minicellulosome in Saccharomyces cerevisiae. FEMS Yeast Res 2009, 9:1236-1249.

31. Fan LH, Zhang ZJ, Yu XY, Xue YX, Tan TW: Self-surface assembly of cellulosomes with two miniscaffoldins on Saccharomyces cerevisiae for cellulosic ethanol production. Proc Natl Acad Sci U S A 2012, 109:13260-13265.

32. Mai V, Wiegel J: Advances in development of a genetic system for Thermoanaerobacterium spp.: expression of genes encoding hydrolytic enzymes, development of a second shuttle vector, and integration of genes into the chromosome. Appl Environ Microbio/ 2000, 66:4817-4821.

33. Zverlov W, Klupp M, Krauss J, Schwarz WH: Mutations in the scaffoldin gene, cipA, of Clostridium thermocellum with impaired cellulosome formation and cellulose hydrolysis: insertions of a new transposable element, IS1447, and implications for cellulase synergism on crystalline cellulose. J Bacteriol 2008, 190:4321-4327.

34. Podkaminer KK, Guss AM, Trajano HL, Hogsett DA, Lynd LR: Characterization of xylan utilization and discovery of a new endoxylanase in Thermoanaerobacterium saccharolyticum through targeted gene deletions. Appl Environ Microbiol 2012, 78:8441-8447.

35. Petersen TN, Brunak S, von Heijne G, Nielsen H: SignalP 4.0: discriminating signal peptides from transmembrane regions. Nat Methods 2011, 8:785-786.

36. Morag E, Bayer EA, Lamed R: Unorthodox intrasubunit interactions in the cellulosome of Clostridium-Thermocellum - identification of structural transitions induced in the S1-subunit. Appl Biochem Biotechnol 1992, 33:205-217.

37. Lamed R, Kenig R, Morag E, Yaron S, Shoham Y, Bayer EA: Nonproteolytic cleavage of aspartyl proline bonds in the cellulosomal scaffoldin subunit from Clostridium thermocellum. Appl Biochem Biotechnol 2001, 90:67-73.

38. Yaron S, Shimon LJ, Frolow F, Lamed R, Morag E, Shoham Y, Bayer EA: Expression, purification and crystallization of a cohesin domain from the cellulosome of Clostridium thermocellum. J Biotechnol 1996, 51:243-249.

39. Mechaly A, Fierobe HP, Belaich A, Belaich JP, Lamed R, Shoham Y, Bayer EA: Cohesin-dockerin interaction in cellulosome assembly: a single hydroxyl group of a dockerin domain distinguishes between nonrecognition and high affinity recognition. J Biol Chem 2001, 276:9883-9888. 
40. Demishtein A, Karpol A, Barak Y, Lamed R, Bayer EA: Characterization of a dockerin-based affinity tag: application for purification of a broad variety of target proteins. J Mol Recognit 2010, 23:525-535.

41. Leibovitz E, Beguin P: A new type of cohesin domain that specifically binds the dockerin domain of the Clostridium thermocellum cellulosomeintegrating protein CipA. J Bacteriol 1996, 178:3077-3084.

42. Leibovitz E, Ohayon H, Gounon P, Beguin P: Characterization and subcellular localization of the Clostridium thermocellum scaffoldin dockerin binding protein SdbA. J Bacteriol 1997, 179:2519-2523.

43. Zhao G, Li H, Wamalwa B, Sakka M, Kimura T, Sakka K: Different binding specificities of S-layer homology modules from Clostridium thermocellum AncA, SIp1, and SIp2. Biosci Biotechnol Biochem 2006, 70:1636-1641.

44. Lynd LR, Zhang Y: Quantitative determination of cellulase concentration as distinct from cell concentration in studies of microbial cellulose utilization: analytical framework and methodological approach. Biotechnol Bioeng 2002, 77:467-475.

45. Lu Y, Zhang YH, Lynd LR: Enzyme-microbe synergy during cellulose hydrolysis by Clostridium thermocellum. Proc Natl Acad Sci U S A 2006, 103:16165-16169.

46. Gefen G, Anbar M, Morag E, Lamed R, Bayer EA: Enhanced cellulose degradation by targeted integration of a cohesin-fused beta-glucosidase into the Clostridium thermocellum cellulosome. Proc Natl Acad Sci U S A 2012, 109:10298-10303.

47. Lee JM, Venditti RA, Jameel H, Kenealy WR: Detoxification of woody hydrolyzates with activated carbon for bioconversion to ethanol by the thermophilic anaerobic bacterium Thermoanaerobacterium saccharolyticum. Biomass Bioenerg 2011, 35:626-636.

48. Olson DG, Giannone RJ, Hettich RL, Lynd LR: Role of the CipA Scaffoldin protein in cellulose solubilization, as determined by targeted gene deletion and complementation in Clostridium thermocellum. J Bacteriol 2013, 195:733-739.

49. Winston F, Dollard C, Ricupero-Hovasse SL: Construction of a set of convenient Saccharomyces cerevisiae strains that are isogenic to S288C. Yeast 1995, 11:53-55.

50. Shanks RM, Kadouri DE, MacEachran DP, OToole GA: New yeast recombineering tools for bacteria. Plasmid 2009, 62:88-97.

51. Currie DH, Mcbride J, Guss A: Modified cipA gene from Clostridium thermocellum for enhanced genetic stability. Filed: 4/21/2010. Patent Application Number PCT/US2010/031907.

52. Argyros DA, Tripathi SA, Barrett TF, Rogers SR, Feinberg LF, Olson DG, Foden JM, Miller BB, Lynd LR, Hogsett DA, Caiazza NC: High ethanol titers from cellulose by using metabolically engineered thermophilic, anaerobic microbes. Appl Environ Microbiol 2011, 77:8288-8294.

doi:10.1186/1754-6834-6-32

Cite this article as: Currie et al:: Functional heterologous expression of an engineered full length CipA from Clostridium thermocellum in Thermoanaerobacterium saccharolyticum. Biotechnology for Biofuels 2013 6:32.

\section{Submit your next manuscript to BioMed Central and take full advantage of:}

- Convenient online submission

- Thorough peer review

- No space constraints or color figure charges

- Immediate publication on acceptance

- Inclusion in PubMed, CAS, Scopus and Google Scholar

- Research which is freely available for redistribution

Submit your manuscript at www.biomedcentral.com/submit
Ciomed Central 